Review Article

\title{
A Review on Benzoxazole Containing Heterocyclic Compounds as a Wonder Medication for
} Thousands of Ailments.

\section{Femy Maria K.M*1, Amala Babu², Sneha Antony³, Dr.Vinod b , Dr.Daisy P A ${ }^{5}$}

${ }^{1}$ Student, Department of Pharmaceutical Chemistry, St. Joseph's College of Pharmacy, Dharmagiri Campus, Cherthala, Kerala, India. ${ }^{2}$ Student, Department of Pharmaceutical Chemistry, St. Joseph's College of Pharmacy, Dharmagiri Campus, Cherthala, Kerala, India. ${ }^{3}$ Student, Department of Pharmaceutical Chemistry, St. Joseph's College of Pharmacy, Dharmagiri Campus, Cherthala, Kerala, India. ${ }^{4} \mathrm{HOD}$ and Professor, Department of Pharmaceutical Chemistry, St. Joseph's College of Pharmacy, Dharmagiri Campus, Cherthala, Kerala, India.

${ }^{5}$ Principal, HOD and Professor, Department of Pharmaceutics, St. Joseph's College of Pharmacy, Dharmagiri Campus, Cherthala, Kerala, India.

*Corresponding author's E-mail: femymariakm@gmail.com

Received: 14-06-2021; Revised: 22-08-2021; Accepted: 30-08-2021; Published on: 15-09-2021.

\section{ABSTRACT}

The benzoxazole is a heterocyclic aromatic organic compound. It is a vital pharmacophore and honoured structure in medicinal chemistry. It plays a very imperative role with quite useful therapeutic activities such as antiulcers, antihypertensives, analgesic, antiinflammatory, anti-virals, antifungals, anticancer, antidepressant activity, antilishmanial activity, anticonvulsant activity, antitubercular activity, antitumor activity, The review of the literature reveals that the benzoxazole derivatives are marvellously effective compounds and a large number of reviews available for biochemical and pharmacological studies established that their molecules are useful against a wide variety of microorganisms. Because of their prominence, the techniques for their synthesis have become an attention of synthetic organic chemists. Therefore, in the contemporary review we tried to assemble the chemistry of different derivative of substituted benzoxazole as well as various pharmacological activities and some of the important methodologies used for the synthesis.

Keywords: Benzoxazole, Coumarin, Anti-inflammatory, Anti-microbial, Anti-cancer.

QUICK RESPONSE CODE $\rightarrow$

DOI:

10.47583/ijpsrr.2021.v70i01.022

DOI link: http://dx.doi.org/10.47583/ijpsrr.2021.v70i01.022

\section{INTRODUCTION}

R

esearch in the field of pharmaceutical chemistry has its most imperative task in the development of new and better medications and their fruitful introduction into clinical practice. The word 'drug' is derived from the French word 'drogue' that means a dry herb. The root of understanding in the medicinal chemistry lies in wakefulness of the relation between the chemistry of a particular compound or group of compounds and their interactions with the body, which is known as structure activity relation and the mechanism by which the compound affects the biological system, known as its mode of action. Heterocycles are among the most habitually encountered skeletons in drugs and pharmaceutically relevant substances. The astonishing capability of heterocyclic nuclei to serve both as biomimetics and reactive pharmacophores has chiefly contributed to their irreplaceable value as traditional vital elements of numerous drugs. The improvement of heterocycles as scaffolds, containing a high degree of diversity has turn out to be a leading focus in modern drug discovery. The synthetic heterocyclic drugs are still more abundant and include most of the hypnotics, anticonvulsants, analeptics, antihistaminics, antithyroid drugs, also many antiseptics, fungicides, vasopressor modifiers. Most of the compounds we know as synthetic drugs such as diazepam, chlorpromazine, isoniazid, metronidazole, azidothymidine, barbiturates, antipyrine, captopril and methotrexate are heterocycles ${ }^{1}$.

Benzoxazole is an aromatic organic compound consisting of a benzene fused oxazole ring structure. Its derivatives are known to exhibit various biological activities such as anticancer, antimicrobial, anti-HIV and dopamine D4 agonists etc. They are also remarkable fluorescent probes which show high Stokes shift and present thermal and photophysical stability due to an excited state intramolecular proton transfer mechanism. They can be measured as structural bio isosteres of naturally occurring nucleotides such as adenine and guanine, which allow them to interact easily with the biopolymers of a living system. They have revealed low toxicity in warm-blooded animals. Benzoxazoles possess a large number of optical applications such as photoluminescent, whitening agents and dye laser and also found applications as intermediates for organic synthesis. Research in this area is still veiled and is directed towards the synthesis of compounds with enhanced biological activity². 
Chemistry

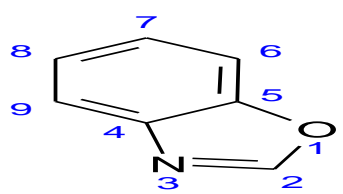

- Benzoxazole, also known as 1-oxa-3-aza-1h-indene, is a member of the class of compounds known as benzoxazoles.

- Benzoxazoles are organic compounds containing a benzene attached to an oxazole ring. Oxazole consists of a five-membered aromatic ring with a nitrogen and an oxygen atom at the 1- and 3position, respectively.

- Its molecular formula is $\mathrm{C}_{7} \mathrm{H}_{5} \mathrm{NO}$ and molar mass is $119.12 \mathrm{~g} / \mathrm{mol}$.

- Benzoxazole is soluble (in water) and an extremely weak basic (essentially neutral) compound (based on its pKa).

- Melting point is $27-30^{\circ} \mathrm{C}$.

- Its odour is similar to pyridine ${ }^{3}$.

\section{Chemical Reactivity of Benzoxazole}

Benzoxazoles are heteroaroamtic compounds and account for a variety of products after reaction with various electrophiles and electron rich species ${ }^{4}$.

\section{Nitration}

Nitration of benzoxazole is carried out using sulphuric acid and nitric acid. Nitration preferentially occurs at $\mathrm{C}_{6}-$ position. Nitration of 2-phenyl benzixazole affords 6-nitro2-phenyl benzoxazole at room temperature ${ }^{4}$.

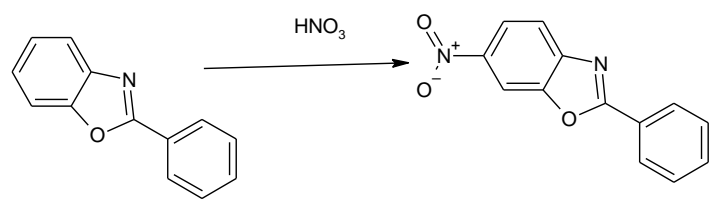

\section{Amination}

Amino group enters at third position of benzoxazole on treating it with hydroxyl amine hydrochloride in $1 \mathrm{M} \mathrm{NaOH}$. Later the resulting amino benzoxazole reacts with $\mathrm{Cl}_{2}$ or $\mathrm{Br}_{2}$ in chloroform to yield corresponding chloro or bromo derivatives ${ }^{4}$.
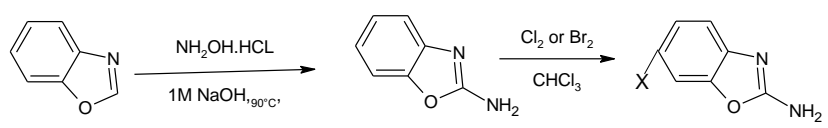

\section{Alkylation}

Alkylation in benzoxazole occur at second position on reaction with secondary alkyl halides in presence of catalyst copper(I) and bis[2-(N,Ndimathylamino)ethyl]ether ${ }^{5}$.

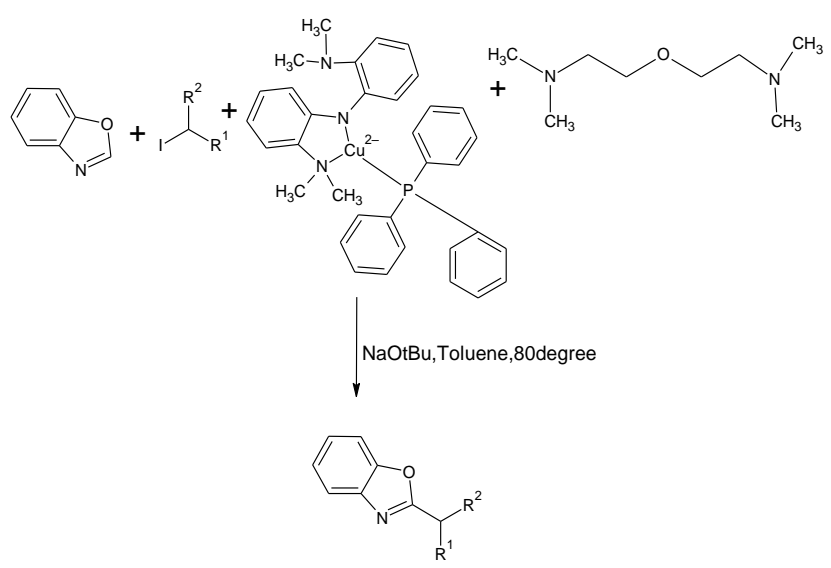

In contrast $\mathrm{N}$-alkylated products are obtained on treating 2-substitured benzoxazoles with alkylating agents like iodomethanes, dialkyl sulphates etc.<smiles></smiles>

\section{Alkynation}

Pd catalysed reactions with gem-dichloroalkenes in presence of catalytic amount of DPEPHos and lithium tertiary butoxide at $120^{\circ} \mathrm{C}$ cause direct alkynation of benzoxazole ${ }^{5}$.

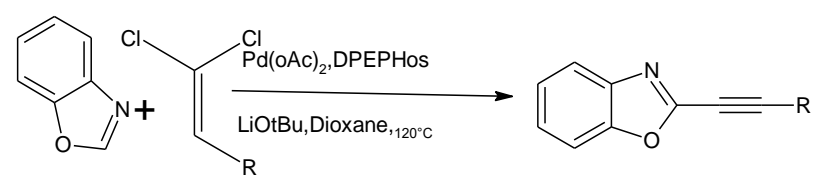

\section{Aryaltion}

On treatment with aryl chlorides in presence of base like lithium tertiary butoxide and palladium catalyst aryl benzoxazoles can be prepared ${ }^{5}$.

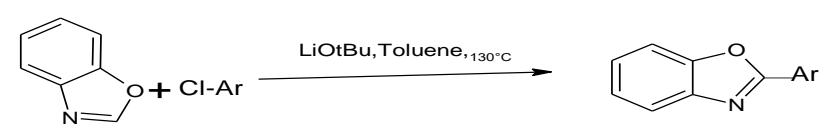

\section{Properties}

$>$ Benzoxazole is an aromatic organic compound with a molecular formula $\mathrm{C}_{7} \mathrm{H}_{5} \mathrm{NO}$, consisting of a benzenefused oxazole ring.

$>$ Its aromaticity makes it relatively stable, though as a heterocycle, it has reactive sites which allow for functionalization.

$>$ It shows various electrophilic reactions and substitution mainly occurs at 2,3,6 positions.

$>$ Prescence of electron withdrawing group favours halogenation ${ }^{6,7}$.

\section{Synthetic Methods of Benzoxazole}

$\checkmark$ Copper catalyzed one-pot synthesis of benzoxazoles using bromoanilines and acyl halides in the presence of a base and a solvent was carried out. An 
intermediate was formed which finally gave pure benzoxazoles (21-97\%) isolated yields, unveiling a broad range of biological activities. They can also be used as antecedents in the synthesis of drugs ${ }^{9}$.

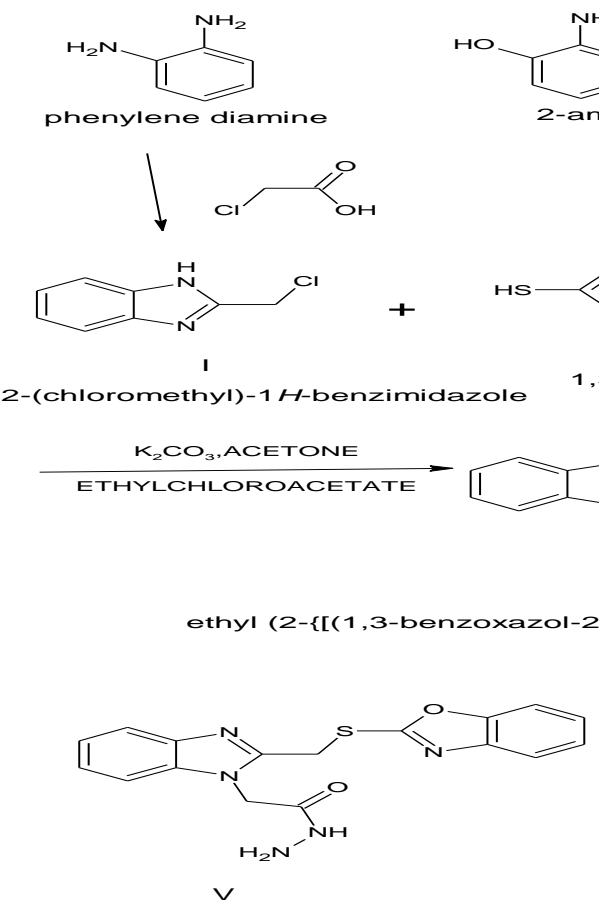

a




\section{Scheme II}

To begin with, reaction of substituted aniline with chloroacetyl chloride in the presence of acetone and powdered potassium carbonate 2-chloro-N-(substituted phenyl)acetamide (I) was prepared. Reaction was carried out between I in dry DMF and sodium azide at room temperature to prepare 2-azido-N-(substituted phenyl)acetamide (II). From 2-aminophenol in methanol, potassium hydroxide followed by the addition of CS2 benzo[d]oxazole-2-thiol (III) was prepared. To a solution of III in acetone anhydrous potassium carbonate powder was added followed by slow addition of 3-bromoprop-1-yne at $0{ }^{\circ} \mathrm{C}$ and 2-(prop-2-yn-1-ylthio) benzo[d]oxazole (IV) was obtained. To end with, II and IV were dissolved in a mixture of $\mathrm{t}-\mathrm{BuOH}: \mathrm{H}_{2} \mathrm{O}$ :DMF followed by the addition of sodium ascorbate and copper (II) sulfate so to obtain target benzoxazole derivatives $(1-20)^{14}$.
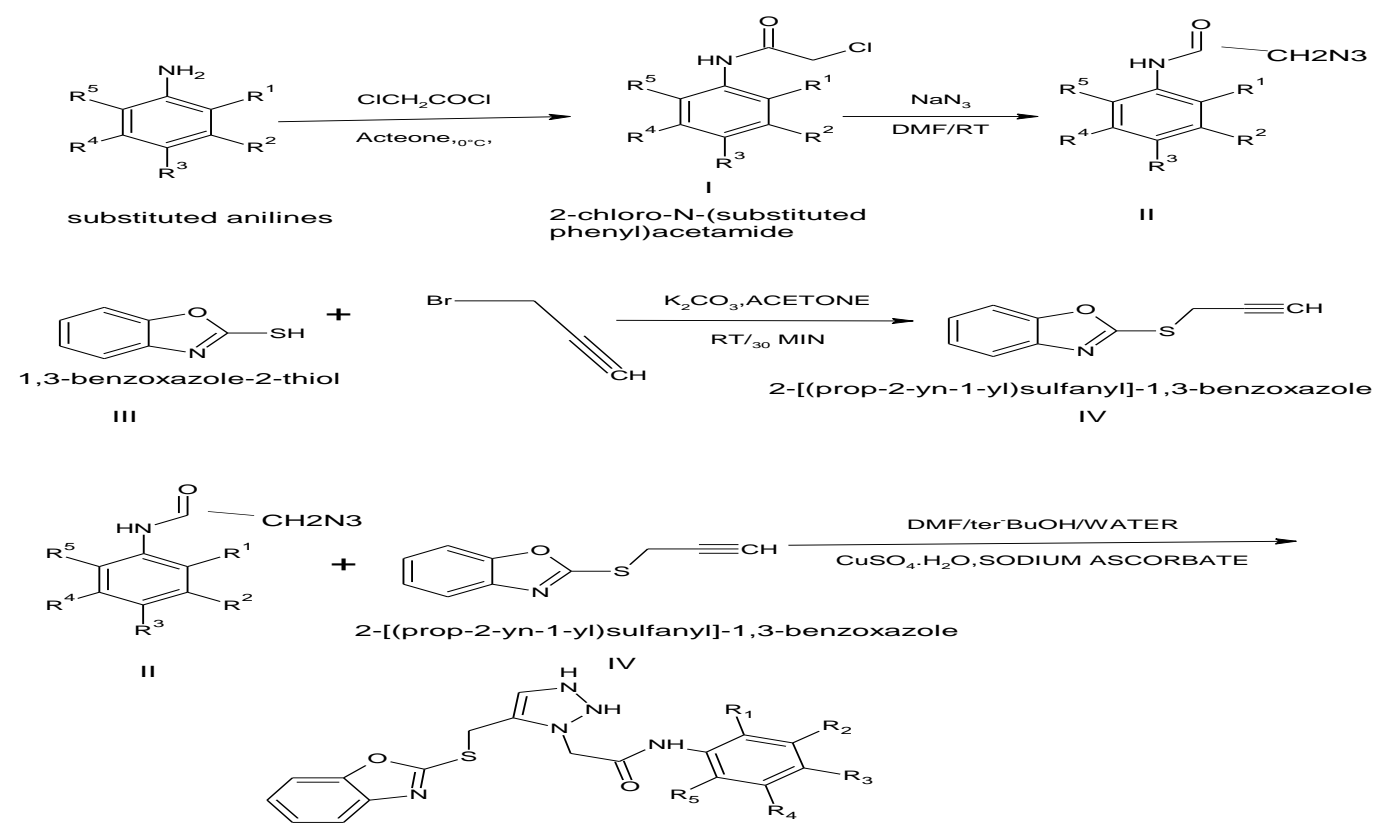

Benzoxazole derivatives (1-20)

\section{Scheme III}

In first step, various substituted phenols (1a-1e) were condensed with citric acid to yield coumarin-4-acetic acid derivatives (2a-2e) as intermediates. Stirring oaminophenol and cyanogen bromide ( $\mathrm{CNBr}$ ) for $48 \mathrm{~h}$ in methanol at room temperature 2-Aminobenzoxazole (3) was produced. By refluxing intermediates $2 a-2 e$ with oaminophenol in the presence of catalyst for $15 \mathrm{~min}$ the first series of test compounds (4a-4e) were synthesized. For synthesis of compounds $4 \mathrm{a}$ and $4 \mathrm{~b}$ Polyphosphoric acid (PPA) was used as catalyst whereas for synthesis of compounds $4 \mathrm{c}-4 \mathrm{e}$ orthophosphoric acid (OPA) was used, as PPA being stronger acid leads to oxidation of the products. By coupling the two intermediates, $2 a-2 e$ and 3 , under anhydrous conditions the second series of test compounds 5a-5e was synthesized using dicyclohexylcarbodiimide (DCC) as coupling agent ${ }^{15}$.

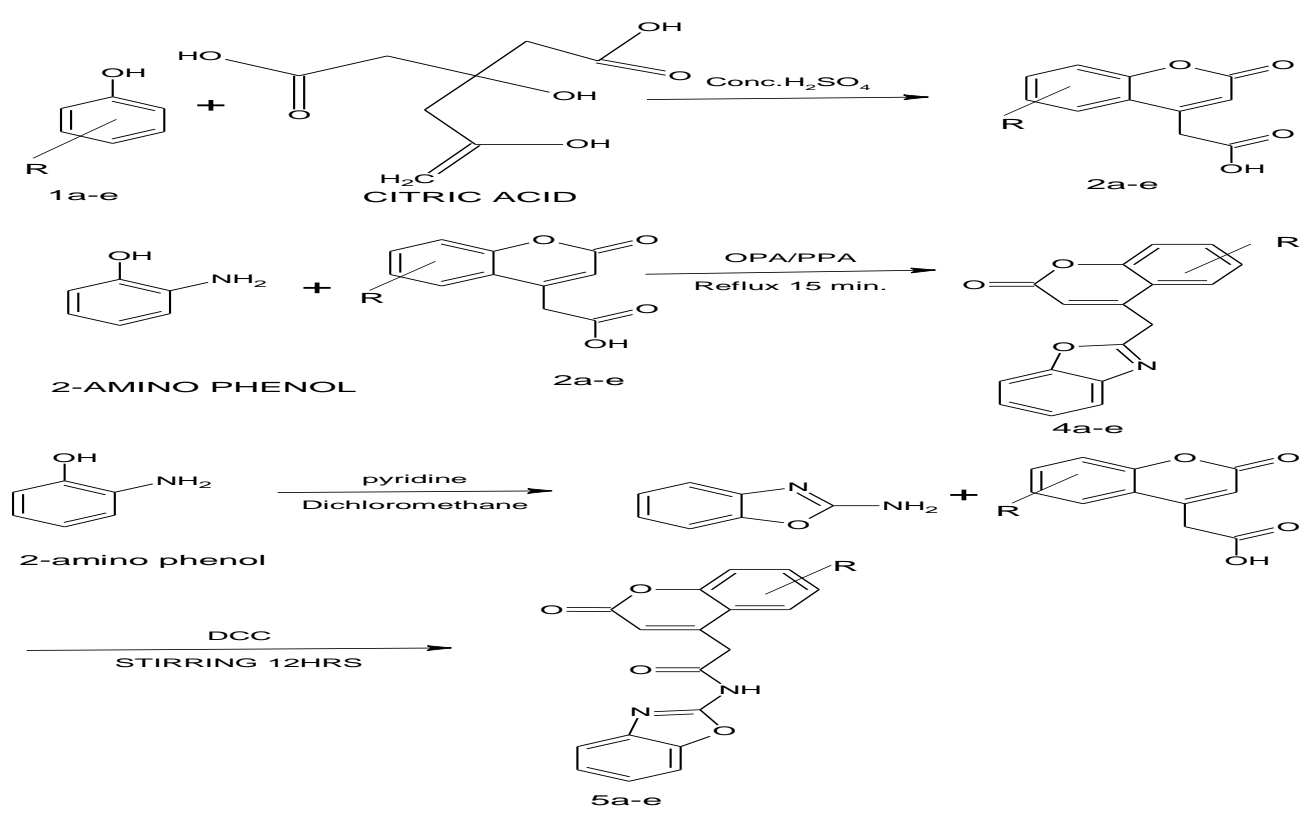




\section{Biological Activities}

\section{Anti-Microbial Activity}

A)Balasubrahmanian $\mathrm{N}$ et.al; reported the synthesis of 2(2-((benzoxazol-2-ylthio) methyl)-1H-benzimidazol-1-yl) acetohydrazide derivatives. The anti-microbial activity of synthesized compounds was assessed using Tube dilution method for the determination of minimum inhibitory concentration (MIC) of the synthesized derivatives (1$26)^{16}$. Ofoxacin and fuconazole was used as standard drugs against seven microbial species i.e. B. subtilis (MTCC-441), E. coli (MTCC-443), P. aeruginosa (MTCC-424), S. typhi (MTCC-98), K. pneumoniae (MTCC-530), Candida albicans (MTCC-227) and A. niger (MTCC281).

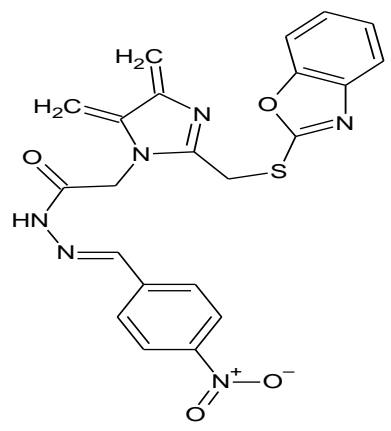

B)N.Balasubrahmanian et.al; reported the synthesis of benzoxazole derivatives. Their antimicrobial potential against selected Gram-positive (S. aureus, B. subtilis), Gramnegative (E. coli, K. pneumoniae, S. typhi) bacterial and fungal (C. albicans, $A$. niger) organisms were measured using tube dilution method ${ }^{17}$.<smiles>O=C(CN1NNC=C1CSc1nc2ccccc2o1)Nc1ccccc1[N+](=O)[O-]</smiles>

\section{Anti- Cancer Activity}

A)Balasubrahmanian $\mathrm{N}$ et.al; reported the synthesis of 2(2-((benzoxazol-2-ylthio) methyl)-1H-benzimidazol-1-yl) acetohydrazide derivatives. Human colorectal carcinoma [HCT116 (ATCC (American Type Culture Collection) CCL247)] cancer cell line was used for the determination of anticancer activity of the prepared derivatives using 2-(3diethyl-amino-6-diethylazaniumylidene-xanthen 9-yl)-5sulfobenzene-sulfonate (SRB) assay.

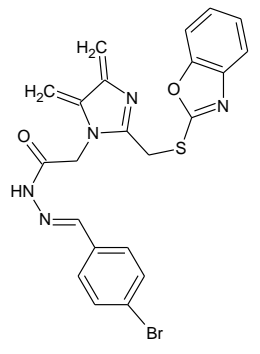

Trichloroacetic acid was used in this study for fixing the cells and then staining was done for 30 min using $0.4 \%$ $(\mathrm{w} / \mathrm{v})$ sulforhodamine $\mathrm{B}$ mixed with $1 \%$ acetic acid. To discard the unbound dye five washes of $1 \%$ acetic acid solution was carried out and was extracted with $10 \mathrm{mM}$ unbuffered tris base solution was used for extraction of protein-bound dye ${ }^{18}$.

B) N.Balasubrahmanian et.al; reported the synthesis of benzoxazole derivatives. Antiproliferative activity of the benzoxazole derivatives was measured against the human colorectal cancer cell line (HCT 116 (ATCC CCL-247). The standard drug used aws 5-fuorouracil (IC50=12.2 $\mu \mathrm{M})^{18}$.<smiles>O=C(CN1NNC=C1CSc1nc2ccccc2o1)Nc1ccccc1</smiles>

\section{Anti-Inflammatory Activity}

Yogita banzal et.al; reported the synthesis of coumarinbenzoxazole derivatives and evaluated its antiinflammatory activity.

In-vitro activity- Invitro anti-inflammatory activity was measured using hRBC membrane stabilization method.

In-vivo activity- It was measured using formalin-induced rat paw-edema model ${ }^{19}$.

\section{Marketed formulations}

\section{Flunoxaprofen}

$\checkmark \quad$ Non-steroidal anti-inflammatory drug.

$\checkmark$ Brand name-priaxim.

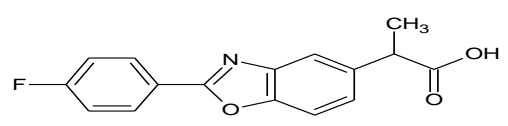

\section{Calcimycin}

- Antibiotic.

- Calcimycin induces $\mathrm{Ca}^{2+}$-dependent cell death by raising intracellular calcium concentration. Calcimycin inhibits the growth of Gram-positive bacteria and some fungi. It also inhibits the activity of ATPase and uncouples oxidative phosphorylation (OXPHOS) of mammalian cells ${ }^{2}$.

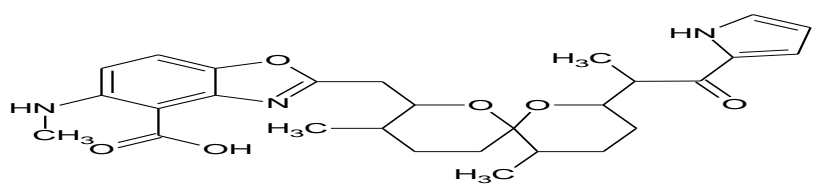

Benoxaprofen

$>$ Non-steroidal anti-inflammatory drug.

$>$ Brand name-oraflex. 


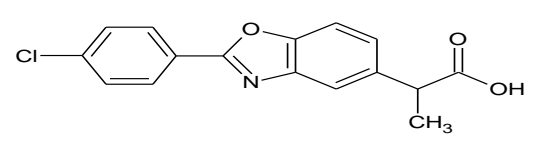

Chloroxazole

- NSAID<smiles>O=c1[nH]c2ccc(Cl)cc2o1</smiles>

\section{Medicinal importance of benzoxazole nucleus}

During recent years there have been some fascinating developments in the biological activities of benzoxazole derivatives. These compounds have special implication in the field of medicinal chemistry due to their incredible pharmacological potentialities.

\section{CONCLUSION}

Alterations on the benzoxazole nucleus have created a large number of compounds having varied pharmacological activities. The synthesis, structures and biological activities of benzoxazole derivatives have long been engrossed of research interest in the field of medicine, due to potential activities shown by them. The biological profiles of these new generations of benzoxazoles signify much progress with regards to older compounds. Looking into the medicinal importance of benzoxazole moiety, it will be worthwhile to synthesize certain newer derivatives of benzoxazole and screen them for their biological activities ${ }^{11}$.

\section{REFERENCES}

1. Ranjith R. The chemistry and biological significance of imidazole, benzimidazole, benzoxazole, tetrazole and quinazolinone nucleus. Journal of Chemical and pharmaceutical Research. 2016; 8(5): 50526.

2. Lokwani P, Nagori BP, Batra N, Goyal A, Gupta S, Singh N. Benzoxazole: The molecule of diverse biological activities. J. Chem. Pharm. Res. 2011; 3(3): 302-11.

3. Ghoshal T, Patel TM. Anticancer activity of benzoxazole derivative (2015 onwards): a review. Future Journal of Pharmaceutical Sciences. 2020 Dec; 6(1): 1-24.

4. Paliwal R, Bhargava S. A review on synthesis and various reaction of benzoxazole. International Journal of Advanced Research in Pharmaceutical \& Bio Sciences. 2014 Jan 1; 4(1): B1-.

5. Lester RP, Bham T, Bousfield TW, Lewis W, Camp JE. Exploring the reactivity of 2-trichloromethylbenzoxazoles for access to substituted benzoxazoles. The Journal of organic chemistry. 2016 Dec 16; 81(24): 12472-7.
6. Liu G, Ren L, Zhang M, Du S, Chen P, Gao A, Chen X, An Z. Synthesis and properties of benzoxazole-based liquid crystals containing ethynyl group. Liquid Crystals. 2020 Sep 25; 47(12): 1719-28.

7. Aiello S, Wells G, Stone EL, Kadri H, Bazzi R, Bell DR, Stevens MF, Matthews CS, Bradshaw TD, Westwell AD. Synthesis and biological properties of benzothiazole, benzoxazole, and chromen-4-one analogues of the potent antitumor agent 2-(3, 4-dimethoxyphenyl)5-fluorobenzothiazole (PMX 610, NSC 721648). Journal of medicinal chemistry. 2008 Aug 28; 51(16): 5135-9.

8. Kumar RV. Synthetic strategies towards benzoxazole ring systems: A review. Asian J. Chem. 2004 Jul 1; 16(3-4): 1241-60.

9. Gupta M, Paul S, Gupta R. General Characteristics and Applications of Microwaves in Organic Synthesis. Acta Chimica Slovenica. 2009 Dec $1 ; 56(4)$.

10. Katritzky AR, Wang Z, Hall CD, Akhmedov NG, Shestopalov AA, Steel PJ. Cyclization of $\alpha$-Oxo-oximes to 2-Substituted Benzoxazoles. The Journal of organic chemistry. 2003 Nov 14; 68(23): 9093-9.

11. Laeeq SH, Sirbaiya AK, Siddiqui HH. Benzoxazole: progress report on chemistry, synthesis and biological activities. Indo American journal of Pharmaceutical Research. 2013; 3(12): 8550-62.

12. Lok R, Leone RE, Williams AJ. Facile rearrangements of alkynylamino heterocycles with noble metal cations. The Journal of Organic Chemistry. 1996 May 17; 61(10): 3289-97.

13. Kakkar S, Tahlan S, Lim SM, Ramasamy K, Mani V, Shah SA, Narasimhan B. Benzoxazole derivatives: design, synthesis and biological evaluation. Chemistry Central Journal. 2018 Dec; 12(1): 16.

14. Kakkar S, Kumar S, Narasimhan B, Lim SM, Ramasamy K, Mani V, Shah SA. Design, synthesis and biological potential of heterocyclic benzoxazole scaffolds as promising antimicrobial and anticancer agents. Chemistry Central Journal. 2018 Dec; 12(1): 1-1.

15. Minhas R, Sandhu S, Bansal Y, Bansal G. Benzoxazole-coumarin derivatives: potential candidates for development of safer antiinflammatory drugs. Der. Chemica Sinica. 2017; 8(1): 146-57.

16. Sharma D, Kumar S, Narasimhan B, Ramasamy K, Lim SM, Shah SA, Mani V. 4-(4-Bromophenyl)-thiazol-2-amine derivatives: synthesis, biological activity and molecular docking study with ADME profile. BMC chemistry. 2019 Dec; 13(1): 1-6.

17. Mandal SC, Mandal M. Quality, safety, and efficacy of herbal products through regulatory harmonization. Drug information journal: DIJ/Drug Information Association. 2011 Jan; 45(1): 45-53.

18. Skehan P, Storeng R, Scudiero D, Monks A, McMahon J, Vistica D, Warren JT, Bokesch H, Kenney S, Boyd MR. New colorimetric cytotoxicity assay for anticancer-drug screening. JNCI: Journal of the National Cancer Institute. 1990 Jul 4; 82(13): 1107-12.

19. Fereidoni M, Ahmadiani A, Semnanian S, Javan M. An accurate and simple method for measurement of paw edema. Journal of Pharmacological and Toxicological Methods. 2000 Feb 1; 43(1): 114.

20. Singh S, Veeraswamy G, Bhattarai D, Goo Jl, Lee K, Choi Y. Recent advances in the development of pharmacologically active compounds that contain a benzoxazole scaffold. Asian Journal of Organic Chemistry. 2015 Dec; 4(12): 1338-61.

Source of Support: The author(s) received no financial support for the research, authorship, and/or publication of this article.

Conflict of Interest: The author(s) declared no potential conflicts of interest with respect to the research, authorship, and/or publication of this article.

For any question relates to this article, please reach us at: editor@globalresearchonline.net

New manuscripts for publication can be submitted at: submit@globalresearchonline.net and submit_ijpsrr@rediffmail.com 